\title{
Influence of Thermal Stability of Quartz and the Particle Size distribution of Burden Materials on the Process of Electrothermal Smelting of Metallurgical Silicon
}

\section{NIKOLAY NIKOLAYEVICH ZOBNIN*, ANATOLIY KORNEYEVICH TORGOVETS, IRINA ANATOLYEVNA PIKALOVA, YULIYA SERGEYEVNA YUSSUPOVA, and SERGEY ASIFOGLY ATAKISHIYEV}

\author{
Karaganda State Industrial University, Kazakhstan, 101400, Temirtau, Republic Avenue, 30 \\ Tau-Ken-Temir LLP, Kazakhstan, 100018, Karaganda,Oktyabrsky district, Accounting \\ quarter 018, building 133, Kazakhstan. \\ *Corresponding author E-mail: zobninnn@mail.ru
}

http://dx.doi.org/10.13005/ojc/340265

(Received: December 26, 2018; Accepted: February 01, 2018)

\section{ABSTRACT}

The article describes the thermal stability of quartz deposits in Kazakhstan-Aktas and Sarykul. It is established that the quartz of the Aktas deposit is a raw material with low thermal stability, and quartz is of medium-durability at Sarykul deposit. The complex influence of the thermal stability of this raw material on the technological parameters of smelting of technical silicon under experimental industrial conditions of electrothermal melting in a furnace with a capacity of 30 MVA was studied at LLP "Tau-Ken-Temir" (Kazakhstan). A new method for optimizing the smelting of commercial silicon has been developed, even when using raw materials with low thermal stability. The main idea of the method is that the less thermally stable quartz is used, the more the initial size of its pieces should be. Optimum values of the average size of pieces of quartz-Aktas$(85-95 \mathrm{~mm})$ and Sarykul-(30-40 $\mathrm{mm})$ are obtained.

Keywords: Thermal stability, Quartz, Technical silicon, Smelting.

\section{INTRODUCTION}

Many researchers have studied the phenomenon of change in the granulometric composition of natural quartz as a result of thermal shock $^{1-4}$. This phenomenon is observed practically in the process of smelting of technical silicon, when quartz is loaded into the furnace. This is explained by phase transitions. The leading role here belongs to the conversion of quartz into its modification crystobalite ${ }^{5}$. This transformation is accompanied by a change in the volume of the material. The 
change in volume leads to a violation of the integrity of quartz crystals and the conversion of lump material into dust. The stability of natural quartz to similar transformations was called - thermal stability. The formation of dust disrupts the silicon reduction process in the furnace. This violation is caused by the removal of dust particles from the furnace by rising gas flows. At the same time, the specific energy consumption becomes higher than $12 \mathrm{MW}{ }^{*} \mathrm{~h} / \mathrm{t}$, the recovery of silicon decreases below $80-85 \%$, and the yield of siliceous dust becomes more than $500 \mathrm{~kg} / \mathrm{t}$ of technical silicon. Most of the earlier studies were carried out on a laboratory scale. The study of the effect of quartz thermal stability on the quartz melting indices in industrial conditions is complex in terms of organization and a costly experiment. However, it is necessary to find ways to solve the problems that arise when using quartz with low thermal stability.

Probably the effect of thermal stability of quartz should be considered in conjunction with the granulometric composition of the raw materials. There are different opinions about the size of the raw material particles necessary to achieve optimal melting points. In the literature, there are indications that quartz particles, for melting in furnaces with a capacity of 6.5 MVA -22.5 , should be $20-80 \mathrm{~mm}^{4,6}$; the source ${ }^{6}$ claims that the size of the quartz particles should be $20-100 \mathrm{~mm}$, and the rest of the text has a recommendation for quartz 4-100 $\mathrm{mm}$ and 10-100 $\mathrm{mm}$. The particle size of green coke should be 2-15 $\mathrm{mm}$ according to one author ${ }^{8}$, and in another ${ }^{6}-8-25$ $\mathrm{mm}$ and here ${ }^{6} 0-80 \mathrm{~mm}$. For charcoal, the size of the fraction should be $6-80 \mathrm{~mm}^{6}$, according to another source $-580 \mathrm{~mm}^{8}$. Coal is recommended in fraction 0-80 $\mathrm{mm}^{6}$, chip size -30 * $100 \mathrm{~mm}^{8}$. The greatest divergence is observed with granulometric composition of quartz and green coke. The most common ideas are about the granulometric composition of charcoal. Doubts arise because the recommended limits for these materials allow varying the particle size in 10-12 times. Probably, the optimal granulometric composition of raw materials is not a constant value and depends on the design features of the furnace smelting space, electrical parameters of the furnace transformer and the thermal stability of quartz. In each case, it is necessary to optimize the particle size distribution.

\section{MATERIAL AND METHOD}

The traditional method for determination of thermal stability of quartz includes heating it in a furnace to a temperature of $1300{ }^{\circ} \mathrm{C}$ and keeping siliceous pieces of material sized $20-30 \mathrm{~mm}$ for one hour there ${ }^{1-3}$. If, after cooling, we can notice substantial destruction of material, then this product is considered to be of poor quality for the metallurgical process. If this does not happen, then we shall continue with the rotation of raw quartz in a drum (for $2 \mathrm{~min}$. with the drum rotation speed of 40 RPM) with the subsequent classification of investigated material on sieves sized of $20 \mathrm{~mm}, 10$ $\mathrm{mm}, 4 \mathrm{~mm}$ and $2 \mathrm{~mm}$. If there is extensive destruction (much of the material was less than $10 \mathrm{~mm}$ ), this stuff will work in an ore-thermal furnace worse than heat-resistant quartz. Source ${ }^{5}$ results data for the study of thermal stability of silica raw material only by using heating of samples without subsequent machining in a rotating drum.

LLP "Tau-Ken-Temir" (Kazakhstan) has problems with optimization of the process of production of technical silicon. The company has been working since 2010 in Karaganda. The rawmaterial base of the enterprise is the deposit of quartz "Aktas", located in Ulytau region of Karaganda oblast, $130 \mathrm{~km}$ north-west of Zhezkazgan. The quartz from this deposit is of high purity, making it the most attractive raw material for smelting technical silicon of the highest marks. Total stock of quartz on the field is over 4 million tons, with an annual production volume of 72 thousand tons of veined quartz $z^{8}$.

In addition, the state deposits balance of the Republic of Kazakhstan as on 01.01.2011 takes into account information about the holdings of 19 deposits of rock crystal and quartz raw materials, of which 3 are Akshoky-JSC "SPK", Saryarka "(Karaganda Oblast) and Sarykul-quartz" LLP (Almaty region). Balance reserves of quartz raw materials as on 01.01.2011 on amount of categories $\mathrm{A}+\mathrm{B}+\mathrm{C} 1$ are: Crysorber $-1679.9 \mathrm{t}$, piezooptic quartz $-1891 \mathrm{~kg} /$ monoblock, rock crystal-591.1 t, milky white veined quartz -8082.01 thousand $t$, granulated quartz-104 thousand t.; category C2: Crysorber$1203.2 \mathrm{t}$, piezooptic quartz $-1432 \mathrm{~kg} / \mathrm{monoblock}$, rock crystal-168.2 t, milky white veined quartz- 621.4 thousand $t^{9}$. 
On LLP “Tau-Ken-Temir”reportingfor 2016, annual techno-economic indexes of silicon smelting from Aktas quartz were the following: the technological consumption of electricity per silicon fractions $0-300 \mathrm{~mm}-16.0 \mathrm{MW}^{*} \mathrm{~h} / \mathrm{t}$, extraction of silicon in metal-64.8\%, silica fume outlet-1 t/t silicon. Such indicators significantly worsened the production economy. The basic idea of the planned study was that the lower the thermal resistance of quartz is, the greater must be the original size of its pieces. In this case, the raw materials will manage to pour down fromthe throat into the zone of intensive chemical reactions before they disintegrate into dust. Laboratory research was conducted on thermal stability of quartz from Aktas and Sarykul deposits and industrial research of the influence of the particle size distribution of burden materials on technical-economic indicatorsof the production when using quartz from these deposits.

Table 1: The chemical composition of quartz from Sarykul and Aktas deposits for the period of studies

The name of quartz

Chemical composition, \%

\begin{tabular}{lccccc}
\hline & $\mathrm{SiO}_{2}$ & $\mathrm{Fe}_{2} \mathrm{O}_{3}$ & $\mathrm{Al}_{2} \mathrm{O}_{3}$ & $\mathrm{CaO}$ & $\mathrm{TiO}_{2}$ \\
Aktas & 99.88 & 0.03 & 0.08 & 0.004 & 0.003 \\
Sarykul & 99.91 & 0.06 & 0.01 & 0.01 & 0.001 \\
\hline
\end{tabular}

Laboratory studies on the thermal stability of quartz was conducted in strict accordance with the manufacturer's recommendations, ore-thermal furnaces installed in LLP "Tau-Ken-Temir"- SMSDemag (Germany). The company "SMS Demag" gives granulometric curves obtained from the tests on the quartz with low, medium and high temperature resistance (unpublished data).

These curves allow judging the suitability of thequartz raw material,validated with this technique, for smelting technical silicon.

The chemical composition of Aktas quartz used during this study is listed in Table 1. The content of solid carbon: semi-coke -85-88\%, coal $-48-52 \%$, charcoal-89-92\%. Ash content of all reducing agents ranged from $1.5 \%$ to $5.5 \%$. The composition of the burden: quartz-700 kg, charcoal-214 kg, coal from Shubarkul deposits $-118 \mathrm{~kg}$, Karaganda green coke $-70 \mathrm{~kg}$, wood chips-253 kg.

The study was carried out on one of the two three-electrode ore-thermal furnaces with capacity of 30 MVA. The furnace is powered by three furnace transformers with capacity of 10 MVA each. The transformers are connected individually to each electrode, and each transformer is connected via two electrodes. This means, for example, that there is no possibility of increasing capacity at only one electrode by increasing capacity on one transformer. The design and the material for the high current line, including the electrode column as well as for the furnace roof are highly influencing the specific energy consumption. "SMS Demag" has optimized the high current line system in such a way that minimizes the reactance of the system and reducing the off-times due to maintenance purposes Figure.1. ${ }^{11}$.

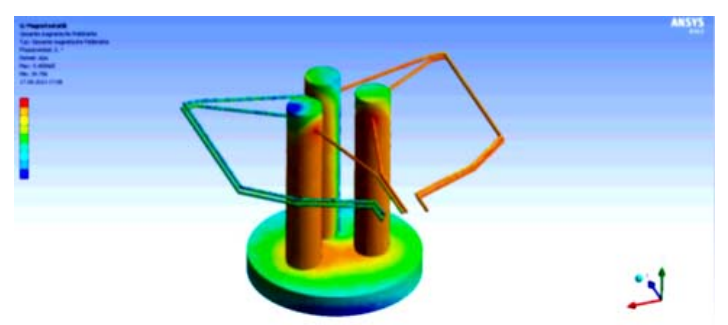

Fig. 1. Simulation of high current system including electrodes ${ }^{11}$

Table 2 shows the electrical characteristics of the furnace transformers used in the study. The working stage of the transformer was the 14th stage. Electric smelting process mode: rated secondary voltage - 215 in (102-105 in with the "landing"), operating current electrode $70-75 \mathrm{kA}$, active power furnace 17-18, MVA, $\cos (\varphi)=0.70-0.75$. Thanks to the innovative scheme for connecting transformers, the value of the phase current is $f 3$ times higher than the nominal value in Table 2 .

Geometrical parameters: the diameter of a smelting bath-6900 mm, total bath depth -3246 $\mathrm{mm}$, height of graphite blocks of crucible part- 1400 $\mathrm{mm}$, diameter of graphite electrodes-1272 mm, distance between the axis of the electrodes-2900 $3250 \mathrm{~mm}$ (during the tests it reached maximum). 
Table 2: Electrical characteristics of the furnace transformers

\begin{tabular}{|c|c|c|c|c|c|}
\hline \multirow[t]{2}{*}{ Stage } & \multirow[t]{2}{*}{ Power, $\mathrm{kV}^{\star} \mathrm{A}$} & \multicolumn{2}{|c|}{ High voltage side } & \multicolumn{2}{|c|}{ Low voltage side } \\
\hline & & Voltage, V & Current, A & Voltage, V & Current, A \\
\hline 1 & 7088 & \multirow{27}{*}{$\begin{array}{l}\text { ㅇ } \\
\text { ○ } \\
\text { ம }\end{array}$} & 202.5 & 145.0 & \multirow{12}{*}{$\begin{array}{l}\text { O } \\
\infty \\
\infty \\
\infty \\
+\end{array}$} \\
\hline 2 & 7352 & & 210.1 & 150.4 & \\
\hline 3 & 7617 & & 217.6 & 155.8 & \\
\hline 4 & 7882 & & 225.2 & 161.3 & \\
\hline 5 & 8147 & & 232.8 & 166.7 & \\
\hline 6 & 8411 & & 240.3 & 172.1 & \\
\hline 7 & 8876 & & 247.9 & 177.5 & \\
\hline 8 & 8941 & & 255.5 & 182.9 & \\
\hline 9 & 9206 & & 263.0 & 188.3 & \\
\hline 10 & 9470 & & 270.6 & 193.8 & \\
\hline 11 & 9735 & & 278.1 & 199.2 & \\
\hline 12 & \multirow{16}{*}{$\begin{array}{l}\text { 응 } \\
\text { ᄋ }\end{array}$} & & & 204.6 & \\
\hline $13 a$ & & & & & \\
\hline $13 b$ & & & & 210.0 & 47619 \\
\hline $13 c$ & & & \multirow{13}{*}{$\begin{array}{l}N \\
\stackrel{\infty}{N} \\
\stackrel{\infty}{0}\end{array}$} & & \\
\hline 14 & & & & 215.4 & 46422 \\
\hline 15 & & & & 220.8 & 45283 \\
\hline 16 & & & & 226.3 & 44199 \\
\hline 17 & & & & 231.7 & 43165 \\
\hline 18 & & & & 237.1 & 42179 \\
\hline 19 & & & & 242.5 & 41237 \\
\hline 20 & & & & 247.9 & 40336 \\
\hline 21 & & & & 253.3 & 39474 \\
\hline 22 & & & & 258.8 & 38647 \\
\hline 23 & & & & 264.2 & 37855 \\
\hline 24 & & & & 269.6 & 37094 \\
\hline 25 & & & & 275.0 & 36364 \\
\hline
\end{tabular}

The furnace bath provides the rotation speed of 5-15 days to one turn. Granulometric composition of other materials is maintained at a constant level. The relevant data are shown in Table 3. The usedwood chips size is $35 * 100 \mathrm{~mm}$. The maintenance of the grain-size composition of carbonaceous reducing agents at a constant level has been one of the most technically complex tasks in this study.

Table 3: Granulometric parameters of carbonaceous reducing agents taken in the research process

\begin{tabular}{|c|c|c|c|c|}
\hline $\begin{array}{l}\text { Material } \\
\text { designation }\end{array}$ & $\begin{array}{c}\text { The main } \\
\text { fraction } \\
\mathrm{mm}\end{array}$ & $\begin{array}{c}\text { Exit of "trivia" } \\
\text { with diameter less } \\
\text { than the lower limit } \\
\text { on input data, \% }\end{array}$ & $\begin{array}{l}\text { Granulometric parameter } \\
\text { Exit of "trivia" with } \\
\text { diameter less than the } \\
\text { lower limit at the endpoin } \\
\text { of burden batching, } \%\end{array}$ & $\begin{array}{l}\text { Average logarithmic diameter } \\
\text { of particles at the endpoint } \\
\text { of burden batching, mm }\end{array}$ \\
\hline $\begin{array}{l}\text { Coal from } \\
\text { Shubarkul } \\
\text { deposits }\end{array}$ & $10-15$ & 3.4 & 15.8 & 11.6 \\
\hline $\begin{array}{l}\text { Charcoal } \\
\text { Karaganda } \\
\text { semi-coke }\end{array}$ & $5-100$ & 4.9 & 32.5 & 36.5 \\
\hline
\end{tabular}




\section{RESULTS AND DISCUSSION}

Figure. 2 presents comparative granulometric curves according to "SMS Demag" and the results of the laboratory study of thermal Aktas and Sarykul Quartz. As can be seen from the data presented, Aktas quartz with fractions $2-10 \mathrm{~mm}$, obtained as the result of research work, can be called raw materials with high thermal durability. However, its indicators deviatein the direction of quartz with low strength, and in the area of $20 \mathrm{~mm}$ they cross the characteristic curve of the quartz with the lowest indicators. Sarykul quartz with fractions of 2-10 mm could be called raw materials with high thermal stability but its temperature resistance can be assessed as intermediate between medium and high. As can be seen from the results of the analysis of the particle size distribution curves of quartz subjected to study on heat resistance, using Sarykul quartz for smelting silicon will provide a significant improvement in the process.

Further industrial investigations were carried out. The first campaign of smelting using Sarykulquartz during 5 days, failed. Purchased quartz with fraction of $20-300 \mathrm{~mm}$ and medium logarithmicparticle diameter of $158 \mathrm{~mm}$ was used.As a result the throat was overfilled with solid slag with a high concentration of silicon oxide. Average logarithmic value was calculated from here onwards because of the significant differences between upper and lower limit dimensions. From this it could be concluded that the particle of quartz during smelting is subjected to two oppositely directed processes - melting of the surface of quartz with the subsequent aggregation on the one hand, and thermal decay on the other hand.

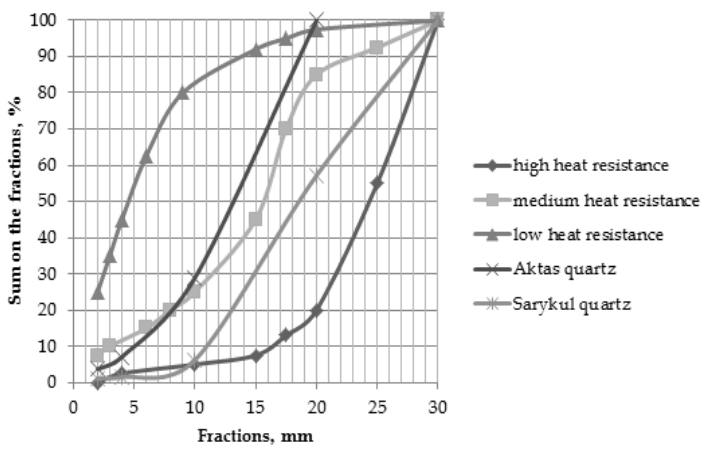

Fig. 2. Granulometric characteristics of Quartz with different heat resistance according to "SMS

Demag" and the results of the study of quartz deposits Aktas and Sarykul
The speed of these processes should be roughly equal. In our case, melting of the surface of quartz particles has led to their merging into a single mass, and to overfilling the throat withsolid slag with a high concentration of silicon oxide.Sufficient organizational work was carried out with raw material suppliers, and several batches of quartz from both deposits with different fractional composition were formed. Several experimental smelting campaigns were held, during which an average logarithmic diameter of quartz pieces was ranged.

The results of the study are presented in Fig.3. On the basis of these results, it can be concluded that adjusting the granulometric parameters of quartz during electrothermal smelting ofsilicon, onecan achieve good results not depending on the thermal stability of raw materials. It is crucial to find the conditions under which the quartz particles reach the zone of intensive chemical reactions until the spillage and carryover from the furnace in the form of dust. For more heatresistant Sarykulquartz, optimum particle size (30$40 \mathrm{~mm}$ ) is less than for less heat-resistant Aktasquartz (85-95 mm).
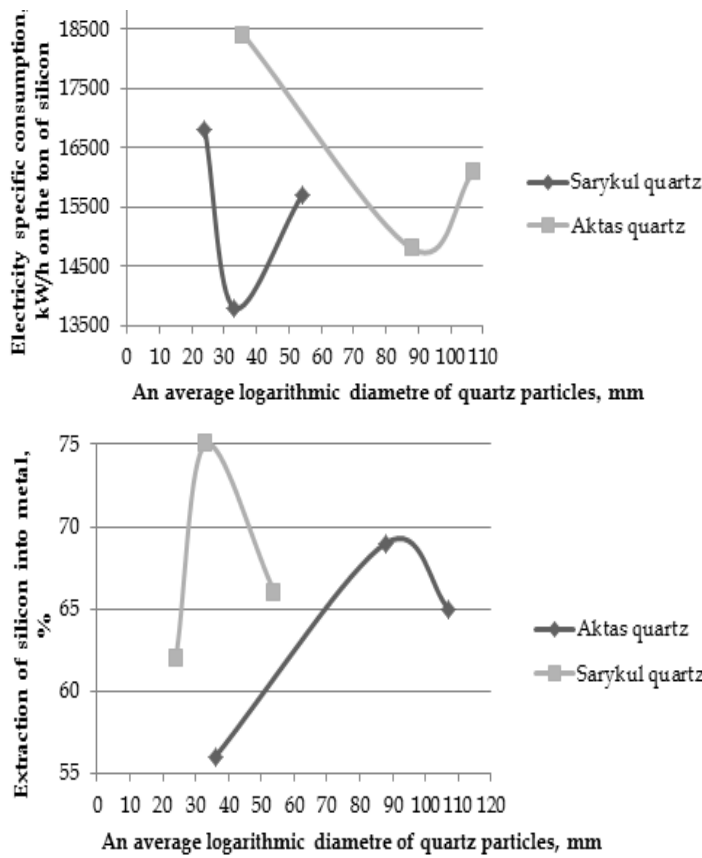

Fig. 3. Dependence of specific power consumption and silicon extraction into metal on the average logarithmic diameter of particles of Sarykul and Aktasquartz 


\section{CONCLUSIONS}

Probably, optimization of particle size distribution of carbon reducing agents is also interesting from a scientific point of view. In practice, however, the fine adjustment of average logarithmic diameter of particles on carbonaceous materials is technically very complicated due to their significant self disintegration during their movement on the tracts of burden batching complexes. Therefore, of practical significance is only optimization ofgranulometric composition of quartz raw materials in metallurgical siliconsmelting. For more heat-resistant Sarykulquartz, optimum particle size $(30-40 \mathrm{~mm})$ is less than for less heat-resistant Aktasquartz (85-95 mm).

\section{ACKNOWLEDGEMENT}

The authors of the article thank the management and employees of LLP "Tau-Ken Temir" for the opportunity to realize their ideas on industrial equipment, organizational and technical support during the research. We hope to continue our long-term and mutually beneficial cooperation.

\section{REFERENCES}

1. Kallfelz, P.L., Quartz for Production of Silicon Metal - Criteria for the Right Choice. Internal report. Elkem ASA, Silicon Division., 2000, 34. 346-355.

2. Malvik, T.; Lund, B., Problems involved with quartzite as a raw material for $\mathrm{FeSi}$ and $\mathrm{Si}$ metal production. Process Mineralogy IX, The Minerals, Metals \& Materials Society. 1990., IX, 499-508

3. Birkeland, R.,Optimal quartz properties method evaluation part 1, report no F10/03. Internal Report, with permission from Elkem (in Norwegian)., 2004, 25. 215-225

4. The basic raw materials for obtaining Silicon. Irkutsk National Research Technical University [electronic resource]. 2017, Access mode: http://www.istu.edu/structure/57/3944/

5. Ringdalen, E., Changes in Quartz During Heating and the Possible Effects on $\mathrm{Si}$ Production. JOM., 2015, 67. 100-105

6. Shkolnikov, A.R.; Fillipov, A.V.; Skornyakov, V.I.; Veselkov, V.V.; Chernykh, E.A.; Zelberg, B.I.,Silicon production. Saint Petersburg., 2001, 269. 150-161.

7. Baysanov, S.O.; Isagulov, A.Z.; Mehdiyev, A.D.; Azbanbaev, E.M., Study of Silicon smelting process using high volatile coal.
G-Global [Electronic resource]. 2017, Access mode:http://group-global.org/ru/publication/ 45890-issledovanie-processa-vyplavki-kremniya -s-primeneniem-dlinnoplamennyh-ugley

8. Silicon production. «Ukrbas» test information web-Portal [Electronic resource]. 2017, Access mode: http://ukrbascompany.at.ua/ index/proizvodstvo_kremnija/0-52

9. About the company. Tau-Ken-Temir Manufacturing of Silicon [Electronic resource]. 2017, Access mode: http://tkstemir.kz/?ctrl=info\&name=company

10. About quartz. The Ministry of investment and development of the Republic of Kazakhstan. Committee of geology and subsurface use [electronic resource]. 2014, Access mode:http://geology.gov.kz/ru/presstsentr/ blog-predsedatelya/vopros-otvet/entry/ kasatelno-kvartsa

11. Degel,R.; Fröhling, Ch.; Kalisch, M.; Hecker, E.; Oterdoom H., Innovative electric smelter solutions of the SMS group for the silicon industry. The Fourteenth International Ferroalloys Congress Energy efficiency and environmental friendlinessare the future of the global Ferroalloy industry., 2015, 4, 122-132. 